\title{
Synthesis and biological evaluation of 1 , 3-dihydroxyxanthone mannich base derivatives as anticholinesterase agents
}

\author{
Jiangke Qin ${ }^{1 *}$, Wenli Lan ${ }^{1}$, Zhong Liư ${ }^{2}$, Jun Huang ${ }^{1}$, Huang Tang ${ }^{1}$ and Hengshan Wang ${ }^{1 *}$
}

\begin{abstract}
Background: Alzheimer's disease (AD), a progressive and degenerative disorder, has become one of the severe problems among the aged population all over the world. To use cholinesterase inhibitor drugs has become the most predominant treatment strategy for $A D$.

Results: A series of novel 1, 3-dihydroxyxanthone Mannich bases derivatives (1a $\sim 4 \mathrm{e})$ were synthesized, structure elucidated and evaluated for anti-cholinesterase activity. The result showed that most of the target compounds exhibited moderate to good inhibitory activities with the $\mathrm{IC}_{50}$ values at micromole level concentration against both acetylcholinesterase (AChE) and butyrylcholinesterase (BuChE). The preliminary structure-activity indicated that: (i) The alkoxy or alkenoxy substituents in the position 3 of xanthone have a positive influence on the inhibition potency; (ii) types of dialkylamine methyl in position 2 of xanthone affected cholinesterase activities and AChE/ BuChE selectivity. Among them, 2-((diethylamino)methyl)-1-hydroxy-3-(3-methylbut-2-enyloxy)-9H-xanthen-9-one showed potent inhibitory activity against $A C h E$ with the $I_{50}$ value of $2.61 \pm 0.13 \mu \mathrm{M}$ and the best inhibitory activity against BuChE with the $I C_{50}$ value of $0.51 \pm 0.01 \mu \mathrm{M}$. The results of a mixed-type manner in enzyme kinetic experiment and molecular docking study for 2-((diethylamino)methyl)-1-hydroxy-3-(3-methylbut-2-enyloxy)-9H-xanthen-9-one demonstrated that the Mannich base derivatives were likely to bind to the active site (AS) and the peripheral anionic site (PAS) of cholinesterases.
\end{abstract}

Conclusions: This study suggested that 1, 3-dihydroxyxanthone Mannich base derivatives were potential dual inhibitors of both AChE and BuChE, which may be considered as a kind of novel drug candidates for treatment of AD.

Keywords: Xanthone, Mannich bases, Synthesis, Cholinesterase inhibitors

\section{Background}

It is well known that there are two major forms of cholinesterases in the brain of mammals. One is acetylcholinesterase (AChE), it is a special enzyme to hydrolyze the neurotransmitter acetylcholine (ACh). The other is butyrylcholinesterase $(\mathrm{BuChE})$, it is a pseudocholinesterase that remains unanswered, which is less substrate specific for ACh than AChE. However, its expressive level was more abundant in the peripheral system. Both of the two cholinesterase are found in neurons and glial cells as well

\footnotetext{
* Correspondence: jiangkeq@sina.com; hshwang2002@126.com

'Key Laboratory of Medicinal Chemical Resources and Molecular Engineering of State Education Ministry, College of chemistry \& Chemical Engineering, Guangxi Normal University, Guilin 541004, P.R. China

Full list of author information is available at the end of the article
}

as in neuritic plaques and tangles in Alzheimer disease (AD) patients [1].

$\mathrm{AD}$ is the most common dementia occurs among the elderly people. It is a progressive and neurodegenerative disorder affects regions of the brain that control cognition, memory, language, speech and awareness [2,3]. The two major pathological hallmarks of $\mathrm{AD}$ are the progressive loss of cholinergic neural transmission, formation of a beta-amyloid plaques (A $\beta$-plaques) that forms senile plaques (SPs) and neurofibrillary tangles (NFTs) of hyperphosphorylated tau protein $[4,5]$. Hence, two hypotheses including cholinergic and $\beta$-amyloid [6-8] were developed to interpret this phenomena, which, in essence, states that the cognitive decline in Alzheimer's disease is due (at least in part) to a loss of cholinergic neurotransmission [9] and the deposition beta-amyloid
(C) Chemistry Central

(c) 2013 Qin et al.; licensee Chemistry Central Ltd. This is an Open Access article distributed under the terms of the Creative Commons Attribution License (http://creativecommons.org/licenses/by/2.0), which permits unrestricted use, distribution, and reproduction in any medium, provided the original work is properly cited. 
protein which is toxic to the neuron system. Anti-A $\beta$ therapies are thought to be a pivotal strategy for the cure of $\mathrm{AD}[10,11]$.

New findings show that both $\mathrm{AChE}$ and BuChE are involved in the breakdown of acetylcholine in the brain. Dual inhibition of these enzymes may increase the efficacy of treatment and broaden the indications. It is demonstrated that $\mathrm{AChE}$ has a key role in the acceleration of $A \beta$-peptide deposition and promoting the formation of A $\beta$-plaques in Alzheimer's brain [12]. Recent studies suggest that BuChE is present in key brain areas and may also influence the aggregation of neuritic $\beta$-amyloid $(A \beta)$ plaques to form the neurofibrillary plaques causing [13-15].

For clinical purposes, it is particularly important to consider the fact that while brain AChE activity continuously declines, BuChE activity increases continuously during disease progression $[16,17]$. Clinical data is therefore mounting to suggest that the use of agents with the ability to effectively inhibit BuChE as well as AChE may represent an additional therapeutic strategy for the ongoing management of AD $[18,19]$.

To date, there are many drugs had been approved and licensed for curing this disease, such as rivastimine, donepezil and galanthamine. At a certain extent, they are generally considered as cholinesterase inhibitors. Although these drugs share the same therapeutic class, they differ in their pharmacology and pharmacokinetics and possess different degree side effects. Moreover, they just cure mild or moderate degree of $\mathrm{AD}$ at the early stage, still no cure for severe type of AD.

Xanthone, chemical name is dibenzo- $\gamma$-pyrone, is a basic building block of active component of many naturally medicinal plants. Its derivatives are broadly distributed in the nature, and with a wide range of biological activities, such as anti-bacterial, anti-inflammatory, antitumour and $\alpha$-glucosidase inhibitory activities [20-23]. Xanthone derivatives as anti-cholinesterase agents have been received significant attention in recent years. It was reported that xanthone derivatives could inhibit AChE and block the Acetylcholinesterase-induced $\beta$-Amyloid aggregation [24-26]. However, there are few reports about the research on xanthone derivates as dual inhibitors of both AChE and BuChE. Recent research showed that macluraxanthone exhibited several hydrophobic interactions and hydrogen bonds with the amino acid residues of the PAS, AS and acyl-binding pocket of AChE and BuChE [27]. Futhermore, Mannich bases have been associated with increased biological potency [28]. So xanthone was used as a building block, and a series of Mannich bases of 1, 3-dihydroxyxanthone analogues with alkoxy and alkenoxy substituted at position 3 of xanthone and dialkylamine methyl substituted at position 2 were designed and synthesized as cholinesterase inhibitors, which possessed dual inhibitory activity to AChE as well as BuChE. Their inhibitory effects on both AChE and BuChE were evaluated. Furthermore, the enzyme kinetic analysis and molecular docking studies were performed to delineate their modes of inhibition.

\section{Results and discussion \\ Chemistry}

The target compounds 1a $\sim 1 \mathbf{e}, \mathbf{2 a} \sim 2 \mathbf{e}, 3 \mathbf{3 a} \sim 3 \mathbf{e}, \mathbf{4 a} \sim \mathbf{4 e}$ were synthesized according to the synthetic route showed in Scheme 1. 1, 3-dihydroxyxanthone was firstly obtained through the one pot reaction using salicylic acid and phloroglucinol as raw material [29,30]. Then, etherification of the hydroxyl in the position 3 of 1,3 dihydroxyxanthone was carried out under alkaline condition, three kinds of intermediate compounds $2 \sim 4$ with different substituents at position 3 were obtained [31]. Finally, compounds $\mathbf{1} \sim \mathbf{4}$ were reacted with formaldehyde and various secondary amines in methanol or acid solution by the Mannich reaction, respectively [32,33], yielded the corresponding Mannich bases of 1 , 3-dihydroxyxanthone derivatives.

For the 1, 3-dihydroxyxanthone and the oxygenated derivatives $(2 \sim 4), 2$ - and 4-position are active sites and the Mannich reaction may be processed in these two position. In order to establish the exact position of substituents of the title compounds, we hypothesis that if the reaction was carried out in the position 2 , the $\mathrm{H}$ of $\mathrm{CH}_{2}$ inducted by Mannich Reaction correlated with $\mathrm{C}-1$ of xanthone ring in $\mathrm{HMBC}$, if not the $\mathrm{H}$ of $\mathrm{CH}_{2}$ correlated with $\mathrm{C}-4 \mathrm{a}$. For validating the hypothesis, 2c was subjected to HSQC and HMBC spectral analysis. The data was shown in Table 1. It was not difficult to confirm the ${ }^{1} \mathrm{H}$ NMR spectral assignments of $2 \mathrm{c}$ by analyzing its coupling relation and comparing its ${ }^{1} \mathrm{H}$ NMR data with that of 1, 3-dihydroxyxanthone [34]. In ${ }^{1} \mathrm{H}$ NMR, the consecutive aromatic protons of A ring were observed at $8.24(\mathrm{~d}, J=7.9 \mathrm{~Hz}, 1 \mathrm{H}), 7.35(\mathrm{t}, J=7.5 \mathrm{~Hz}$, $1 \mathrm{H}), 7.68(\mathrm{t}, J=7.9 \mathrm{~Hz}, 1 \mathrm{H}), 7.40(\mathrm{~d}, J=8.4 \mathrm{~Hz}, 1 \mathrm{H})$; the only reserved proton of $\mathrm{C}$ ring was observed at $6.43(\mathrm{~s}, 1 \mathrm{H})$ which indicated that one of the aromatic protons of $\mathrm{C}$ ring (2- or 4- position) was replaced by the Mannich reaction and the inducted $\mathrm{CH}_{2} \mathrm{~N}$ groups were observed as singlet at $3.76 \mathrm{ppm}$. From HSQC, $\mathrm{HMBC}$ and also comparing its ${ }^{13} \mathrm{C}$ NMR data with that of 1, 3-dihydroxyxanthone [35], its ${ }^{13} \mathrm{C}$ NMR assignments could easy be appointed, in which C-1 and $\mathrm{C}-4 \mathrm{a}$ in xanthone core were observed at 161.70, 157.54 respectively. From the data of $\mathrm{HMBC}$, we can observe that the $\mathrm{H}$ of $\mathrm{CH}_{2} \mathrm{~N}$ correlated with $\mathrm{C}-1$ of xanthone ring, not with $\mathrm{C}-4 \mathrm{a}$, which confirmed that the Mannich reaction was carried out in the position 2. The main connective found in the HMBC was depicted in Figure 1. Other target compounds' spectral data was similar to that of $2 \mathrm{c}$ and all the 

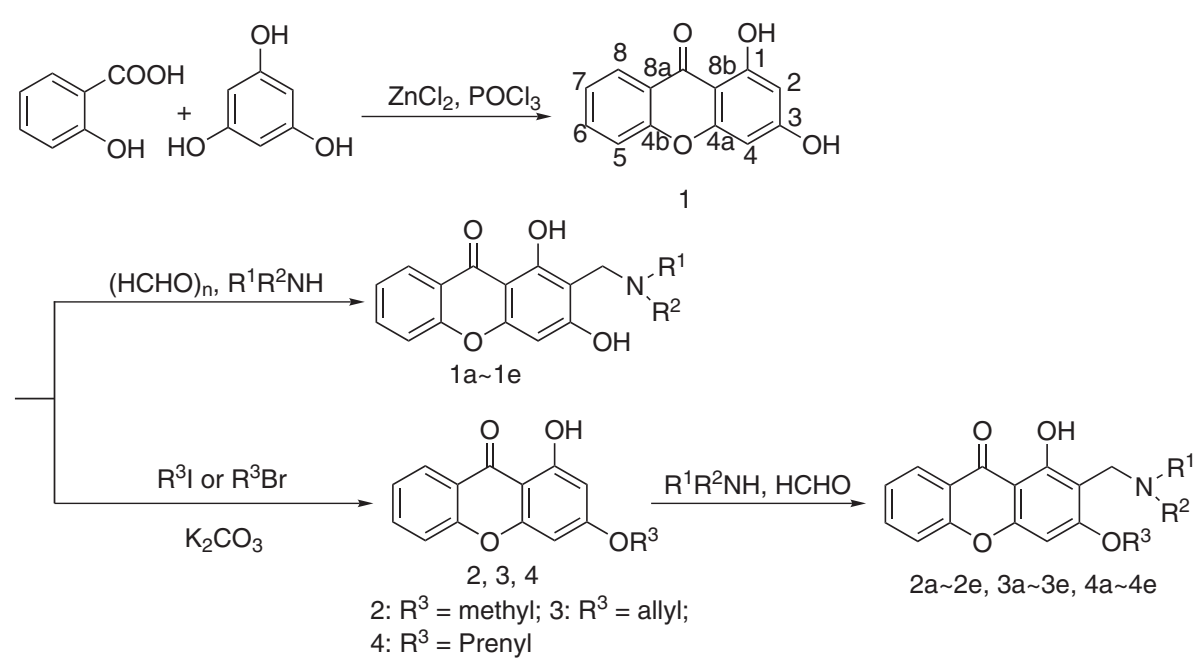

\begin{tabular}{c|ccccc} 
Substituent & $\mathrm{a}$ & $\mathrm{b}$ & $\mathrm{c}$ & $\mathrm{d}$ & $\mathrm{e}$ \\
\hline$-\mathrm{NR}^{1} \mathrm{R}^{2}$ & $-\mathrm{N}^{\prime}$ & $-\mathrm{N}$ & $-N_{4^{\prime}}^{1^{\prime}}$ & $\mathrm{S}_{5^{\prime}}^{2^{\prime}}$ & $\mathrm{N}^{\prime}$
\end{tabular}

Scheme 1 Synthetic route of 1, 3-dihydroxyxanthone mannich base derivatives.

new compounds $(\mathbf{1 a} \sim \mathbf{4 e})$ were characterized by MS, NMR and IR.

\section{Biological activity}

The inhibitory activities of all the synthesized Mannich bases of 1,3-dihydroxyxanthone derivatives against AChE and $\mathrm{BuChE}$ in vitro were tested by slightly modified Ellman method [36], using acetylthiocholine and butyrylthiocholine iodide as substrates and with Galanthamine $\cdot \mathrm{HBr}$ as the reference standard. Inhibition potency of the title compounds toward $\mathrm{AChE}$ and $\mathrm{BuChE}$ was displayed as $\mathrm{IC}_{50}$ values in Table 2 .

From the data listed in the Table 2, we can clearly see that most of the designed compounds exhibited moderate to good inhibitory activities with the $\mathrm{IC}_{50}$ values at micromole level concentration against both of the enzymes.

Some preliminary structure-activity relationships could be summarized as follows: Whether the variety substituent of amido in the position 2 had influences on anti-cholinesterase activity was firstly assessed. The $\mathrm{IC}_{50}$ values were used to draw histogram (Figure 2). As Figure 2 showed, diethylamine methyl in the position 2 of the xanthone exhibited the most potential inhibitory. However, the presence of morpholino methyl showed relatively poor inhibitory activity against both of the enzyme in most case, especially compound $\mathbf{1 e}, \mathbf{2 e}, \mathbf{3 e}$ did not show any inhibition activity at $100 \mu \mathrm{M}$ against BuChE. The influence order could be summarized as follows: diethylamine methyl $\approx$ dimethylamine methyl > pyrrolidinyl methyl $>$ piperidinyl methyl $>$ morpholino methyl against a-cetylcholinesterase activity and diethylamino methyl $>$ pyrrolidinyl methyl $>$ piperidinyl methyl > dimethylamine methyl $>$ morpholino methyl against butyrylcholinesterase activity.

The effects of various substituents in the position 3 were subsequently investigated (Figure 3). Firstly, as for the inhibitory activity against AChE, methoxyl substitution shows the most potent inhibitory, which is consistent with a previous report describing that methoxyl was favorable, although the former report focused on the coumarin moiety [37]. The influence order is methoxyl $>$ prenylated oxyl > allyloxy > hydroxyl. Interestingly, as for the antibutyrylcholinesterase activity, increasing bulkiness of the derivatives, which bear alkenoxy in the position 3 of xanthone exert higher potency. The most active inhibitor against BuChE was $\mathbf{4 b}$ with $\mathrm{IC}_{50}$ value of $0.51 \pm 0.01 \mu \mathrm{M}$, which bears prenyl substituted in the position 3. It also showed potent inhibitory activity against AChE with the $\mathrm{IC}_{50}$ value of $2.61 \pm 0.13 \mu \mathrm{M}$. This result was similar to the Rivera-Becerril's report [38], confirming the double bond of the prenyl group is interacting as a specific $\pi$-hydrogen bond acceptor with the enzyme. The influence order is prenylated oxyl $>$ allyloxy $>$ methoxyl $>$ hydroxyl. In order 
Table 1 The NMR data of compound $2 c$

\begin{tabular}{|c|c|c|c|c|}
\hline Assignment & ${ }^{13} \mathrm{C}$ NMR & ${ }^{1} \mathrm{H}$ NMR & HSQC & HMBC \\
\hline 1 & 161.70 & & & \\
\hline 2 & 104.15 & & & \\
\hline 3 & 165.67 & & & \\
\hline 4 & 90.09 & $6.43(\mathrm{~s}, 1 \mathrm{H})$ & 90.09 & $\begin{array}{c}157.54,104.15 \\
109.21\end{array}$ \\
\hline $4 a$ & 157.54 & & & \\
\hline $4 b$ & 156.21 & & & \\
\hline 5 & 117.76 & $7.40(\mathrm{~d}, J=8.4 \mathrm{~Hz}, 1 \mathrm{H})$ & 117.74 & $121.19,124.27$ \\
\hline 6 & 135.07 & $7.68(\mathrm{t}, J=7.9 \mathrm{~Hz}, 1 \mathrm{H})$ & 135.07 & $126.27,156.21$ \\
\hline 7 & 124.27 & $7.35(\mathrm{t}, J=7.5 \mathrm{~Hz}, 1 \mathrm{H})$ & 124.27 & $117.76,121.19$ \\
\hline 8 & 126.27 & $8.24(\mathrm{~d}, J=7.9 \mathrm{~Hz}, 1 \mathrm{H})$ & 126.27 & $\begin{array}{c}180.96,135.07 \\
156.21\end{array}$ \\
\hline $8 a$ & 121.19 & & & \\
\hline 9 & 180.96 & & & \\
\hline $8 b$ & 109.21 & & & \\
\hline $\mathrm{OCH}_{3}$ & 56.37 & $3.92(\mathrm{~s}, 3 \mathrm{H})$ & 56.37 & 165.67 \\
\hline $\mathrm{CH}_{2} \mathrm{~N}$ & 45.96 & $3.76(\mathrm{~s}, 2 \mathrm{H})$ & 45.96 & $\begin{array}{c}165.67,161.70 \\
109.21,54.24\end{array}$ \\
\hline $1^{\prime}$ and $4^{\prime}$ & 54.24 & 2.63 (brs, 4H) & 54.24 & 23.81 \\
\hline $2^{\prime}$ and $3^{\prime}$ & 23.81 & 1.75 (brs, 4H) & 23.81 & 23.81 \\
\hline
\end{tabular}

to explain the different activities between the AChE and $\mathrm{BuChE}$, the ligand binding sites are considered in both enzymes, such as active site and peripheral anionic site (PAS). In terms of the active sites, it is known that the volume of active site in BuChE is larger than AChE [39-41] and hence can accommodate ligands with larger molecular structures. In PAS, there are a number of hydrophobic amino acids, which in AChE are largely aromatic amino acids while in $\mathrm{BuChE}$ are largely aliphatic [42-44]. In general, the $\mathrm{AChE}$ and BuChE inhibitory activities of etherified compounds with alkyl group in the position 3 are better than those with hydroxyl group. It suggests that hydrophobic circumstance is importance for the anti-cholinesterase activities. The substituents in the position 3 of xanthone show a positive influence on the inhibition potency.

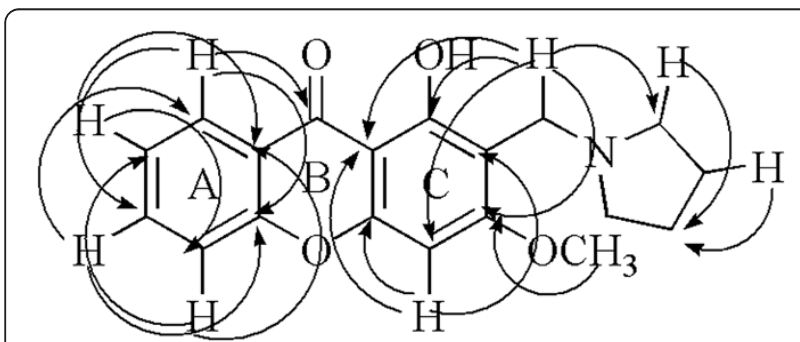

Figure 1 Main connectivities found in the HMBC of Compound 2c.
From Table 2, we also could see that most of the title compounds had BuChE/AChE selectivity index in the range of 0.1-0.8, which suggested that these compounds were potential dual inhibitors of both cholinesterases and showed more inhibitory potency toward BuChE. Because bivalent ChE inhibitors or selective BuChE inhibitors represent a new therapeutic strategy for the on-going management of $\mathrm{AD}[18,19]$, thus they might become a novel kind of potential drug candidates for $\mathrm{AD}$ treatment.

The inhibition modes of both cholinesterases caused by the selected potent compound $\mathbf{4 b}$ were investigated by the graphical analysis of steady-sate inhibition data (Figure 4). Reciprocal plots (lineweaver-Burk plots) describing compounds $\mathbf{4 b}$ inhibition showed that the point of the curves intersect at the secondary quadrant. This pattern indicated the mixed-type inhibition. The results revealed that these compounds were likely to bind both of the active site and PAS of both cholinesterases.

In order to further investigate the binding modes of Mannich bases derivatives with cholinesterases, we carried out molecular docking studies for the selected potent compound $\mathbf{4 b}$ by Surflex-Dock suite implemented in SYBYL 8.0 software. The PDB codes of 3D crystal structures of human $\mathrm{AChE}$ and BuChE are 1EVE and 1P0I, respectively. As shown in Figure 5A, the most energetically favorable binding mode of compound $\mathbf{4 b}$ at the active site of $\mathrm{AChE}$ comes into a free binding energy of $-7.14 \mathrm{kcal} / \mathrm{mol}$. The MOLCAD surface modeling with cavity depth potential shows that compound $\mathbf{4 b}$ extends into the deep cavity of the binding pocket of AChE (Figure 5B). Compound 4b occupied to the central hydrophobic region of the binding pocketed arranged by Tyr70, Tyr121, Trp279 and Phe290. It is clearly demonstrated that compound $\mathbf{4 b}$ extends from the anionic subsite of the active site near Trp84 to PAS region near Trp279. Besides, aromatic ring of compound $\mathbf{4 b}$ also forms $\pi-\pi$ interactions with Trp279 (Figure 5C). Moreover, the dendrimer-shaped motif at the aromatic ring of compound $\mathbf{4 b}$ may effectively prevent the interaction of catalytic triad of $\mathrm{AChE}$ with substrate. These interaction and occupation of compound $\mathbf{4 b}$ with the subsites of AChE explains its mixed inhibition type.

On the other hand, Figure 6A illustrates that the binding energy of the most energetically favorable binding mode of compound $\mathbf{4 b}$ towards the active site of $\mathrm{BuChE}$ is -8.90 $\mathrm{kcal} / \mathrm{mol}$, consistent with the results of enzyme inhibition assay that compound $\mathbf{4 b}$ is more active to $\mathrm{BuChE}$ than to AChE. The MOLCAD cavity depth potential surface also shows that compound $\mathbf{4 b}$ extends into the deep cavity of the binding pocket of $\mathrm{BuChE}$ (Figure 6B). Compound 4b forms three hydrogen bonds with the binding pocket of $\mathrm{BuChE}$. The $\mathrm{CO}$ motif of compound $\mathbf{4 b}$ forms a hydrogen bond with the backbone NH of Gly117 and another one 


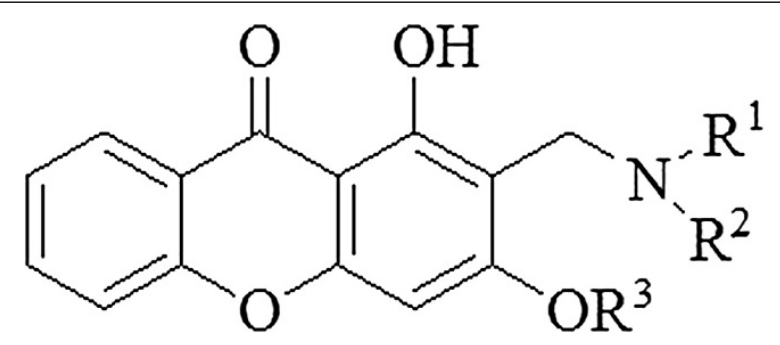

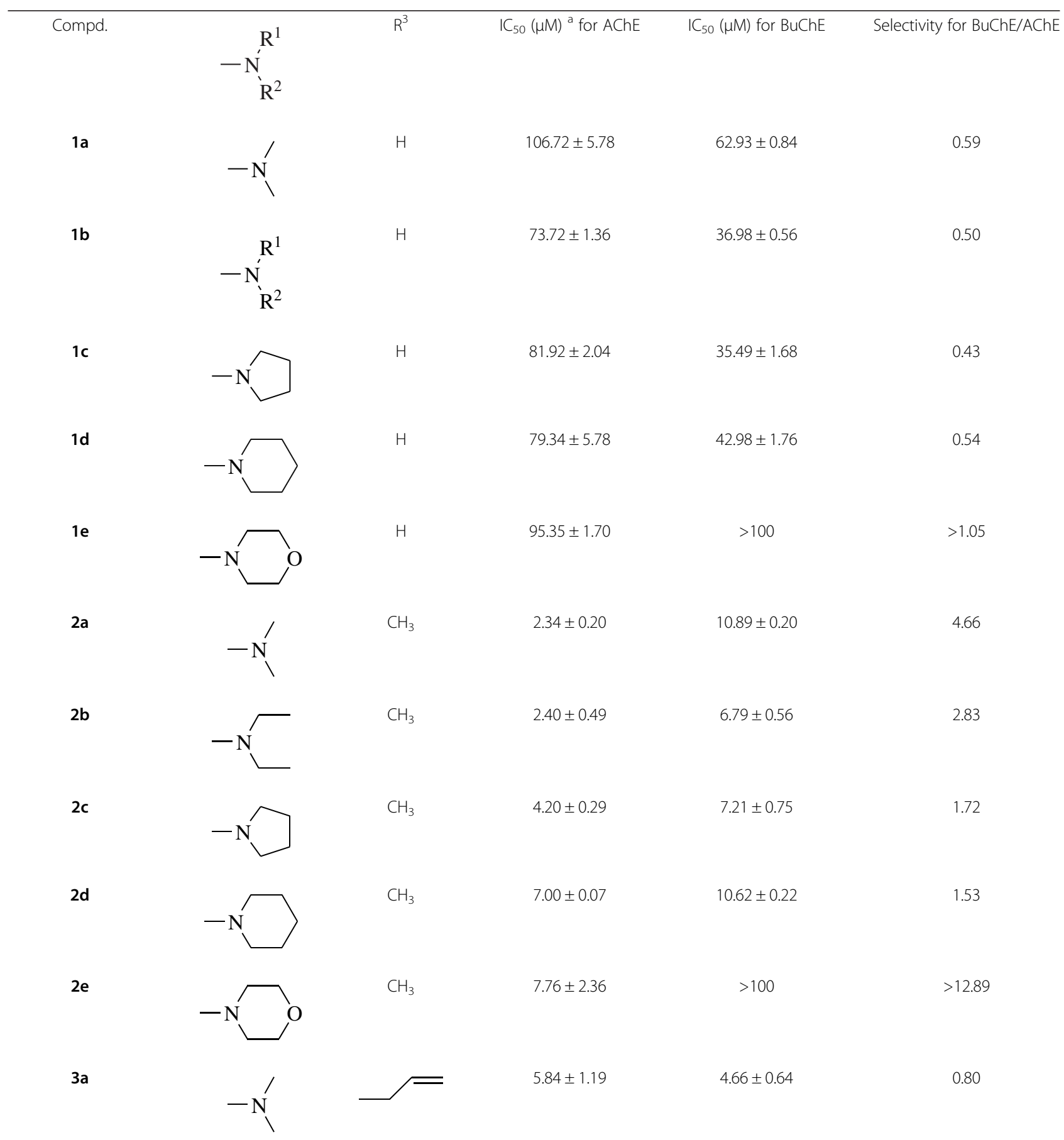


Table 2 Inhibition of AChE and BuChE activities of title compounds (Continued)

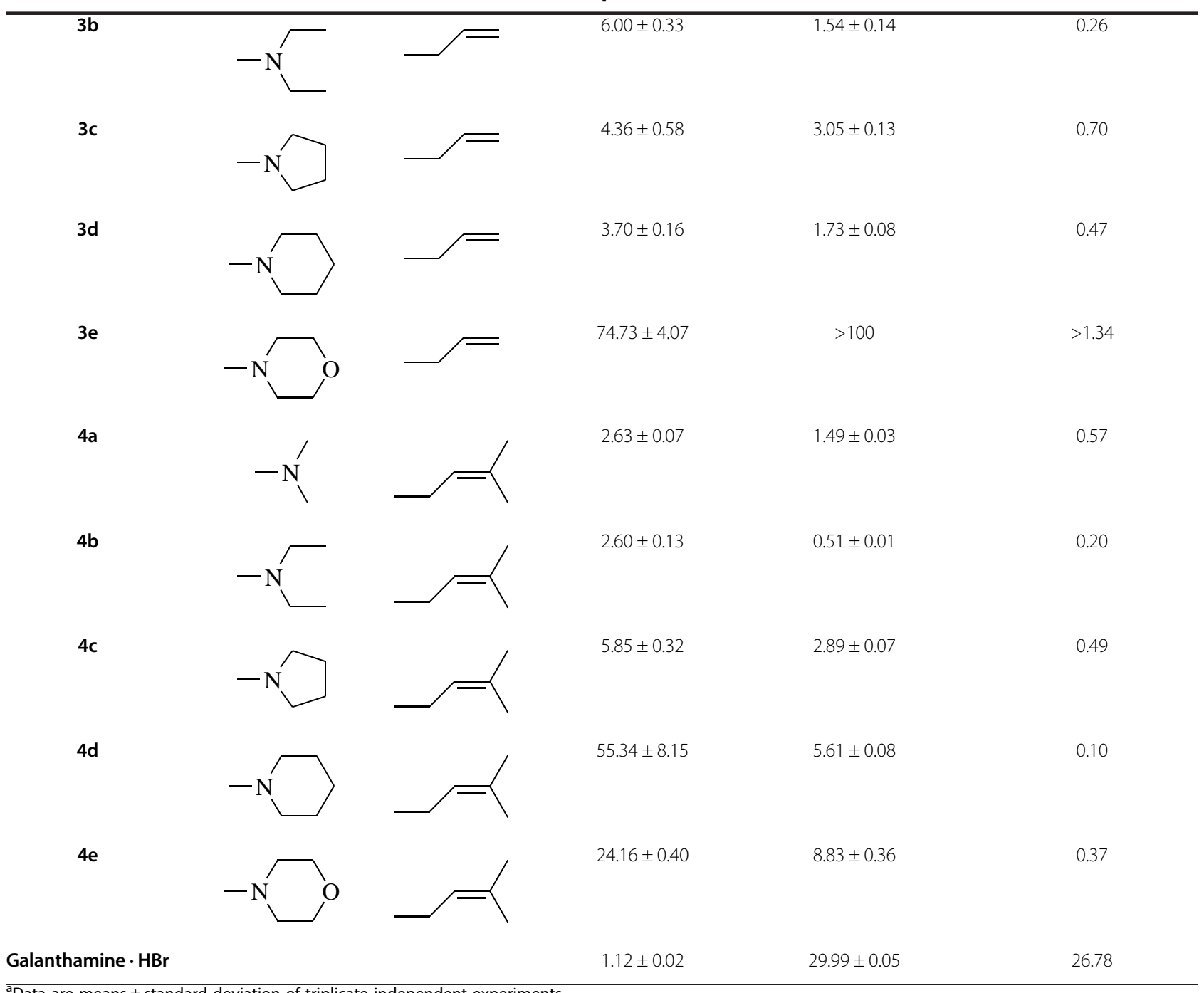

${ }^{\bar{a}}$ Data are means \pm standard deviation of triplicate independent experiments.

with the side chain $\mathrm{OH}$ of Ser198, respectively (Figure 6C). In addition, The $\mathrm{OH}$ groups at the aromatic ring may also interact with Ser198 by forming a hydrogen bond, leading to the attenuation of catalytic ability of BuChE. These $\mathrm{H}$-bonds are believed to contribute to the higher affinity of compound $\mathbf{4 b}$ towards BuChE, which explains why it is more potent than towards AChE.

\section{Experimental \\ Chemistry}

Melting points were measured in X-4 micro-melting point instrument and are uncorrected. IR spectra were taken on Nicolet ESP 360 FI-IR. Direct MS spectra were performed on ESQUIRE HTC instrument in positive mode using $\mathrm{KBr}$ pellets. ${ }^{1} \mathrm{H}$ NMR and ${ }^{13} \mathrm{C}$ NMR spectra were recorded in $\mathrm{CDCl}_{3}$ or Acetone on Bruker AVANCE
AV 500/125 MHz instruments. Chemical shifts are reported as $\delta$ ppm using tetramethylsilane (TMS) as the internal standard and couplings expressed in Hertz. Spin multiplicities are given as follows: $s$ (singlet), d (doublet), $\mathrm{t}$ (triplet), $\mathrm{m}$ (multiplet), or br (broad). Reactions were monitored by thin layer chromatography (TLC) using 0.2 mm Polygram Sil silica gel G254 pre-coated plates with visualization by irradiation with a short-wavelength UV light. Column chromatography was accomplished on Qingdao silica gel (100-200, 200-300 or 300-400 mesh). The process for preparing of title compounds can be found in Additional file 1. HSQC and HMBC spectral analysis of $2 \mathrm{c}$ was taken and the data was showed in Table 1.

\section{Enzyme inhibition assays}

Electric-eel AChE (EC 3.1.1.7), horse-serum BuChE (EC3.1.1.8), acetylthiocholine iodide, butyrylthiocholine 


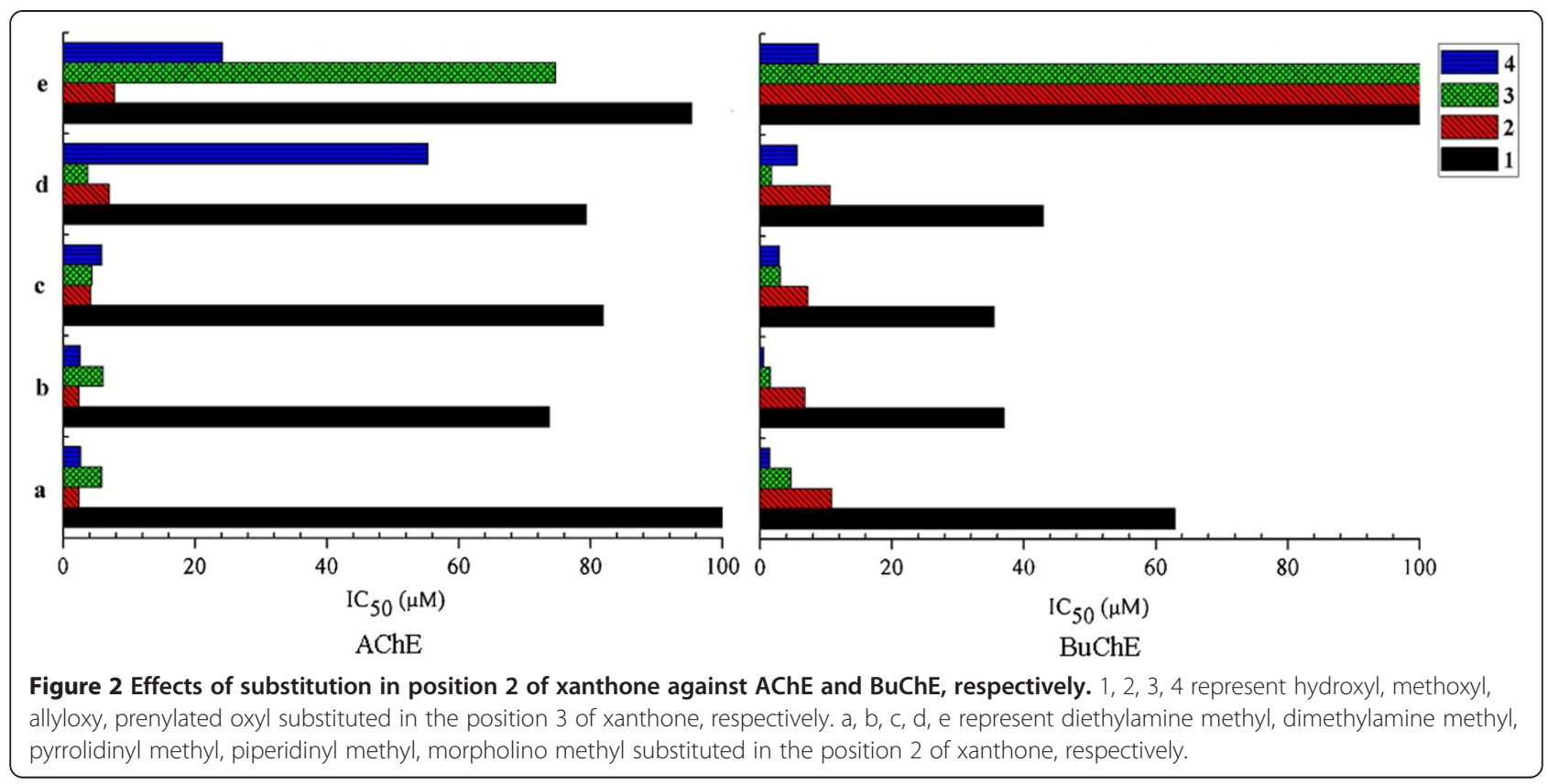

chloride, 5, 5-dithio-bis-nitrobenzoic acid (DTNB) and Galanthamine hydrobromide (galanthamine $\cdot \mathrm{HBr}$ ) were purchased from the Sigma. All other agents were analytical grade. $\mathrm{AChE}$ and $\mathrm{BuChE}$ inhibiting activities were measured by the slight modified spectrophotometric method of Ellman using a 96-well plate reader [36]. Acetylthiocholine iodide and butyrylthiocholine chloride were used as substrates for $\mathrm{AChE}$ and $\mathrm{BuChE}$, respectively. The total volume of tested solution in each well was $150 \mu \mathrm{L}$. These containing phosphate buffer $118 \mu \mathrm{L}$
(0.1 M, pH 8.0), DTNB $6 \mu \mathrm{L}(4 \mathrm{mg} / \mathrm{mL}$ for AChE or $8 \mathrm{mg} / \mathrm{mL}$ for BuChE), different concentration of tested compounds solution $15 \mu \mathrm{L}$ and AChE or BuChE solution $5 \mu \mathrm{L}$, were mixed and incubated for $15 \mathrm{~min}$ at $37^{\circ} \mathrm{C}$. The reaction was then measured followed by the addition of acetylthiocholine or butyrythiocholine solution $(2 \mathrm{mg} / \mathrm{mL}$ or $4 \mathrm{mg} / \mathrm{mL}$, respectively) $6 \mu \mathrm{L}$. The hydrolysis of acetylthiocholine and butyrylthiocholine were monitored by the formation of yellow 5-thio-2nitrobenzoate anion as a result of the reaction between

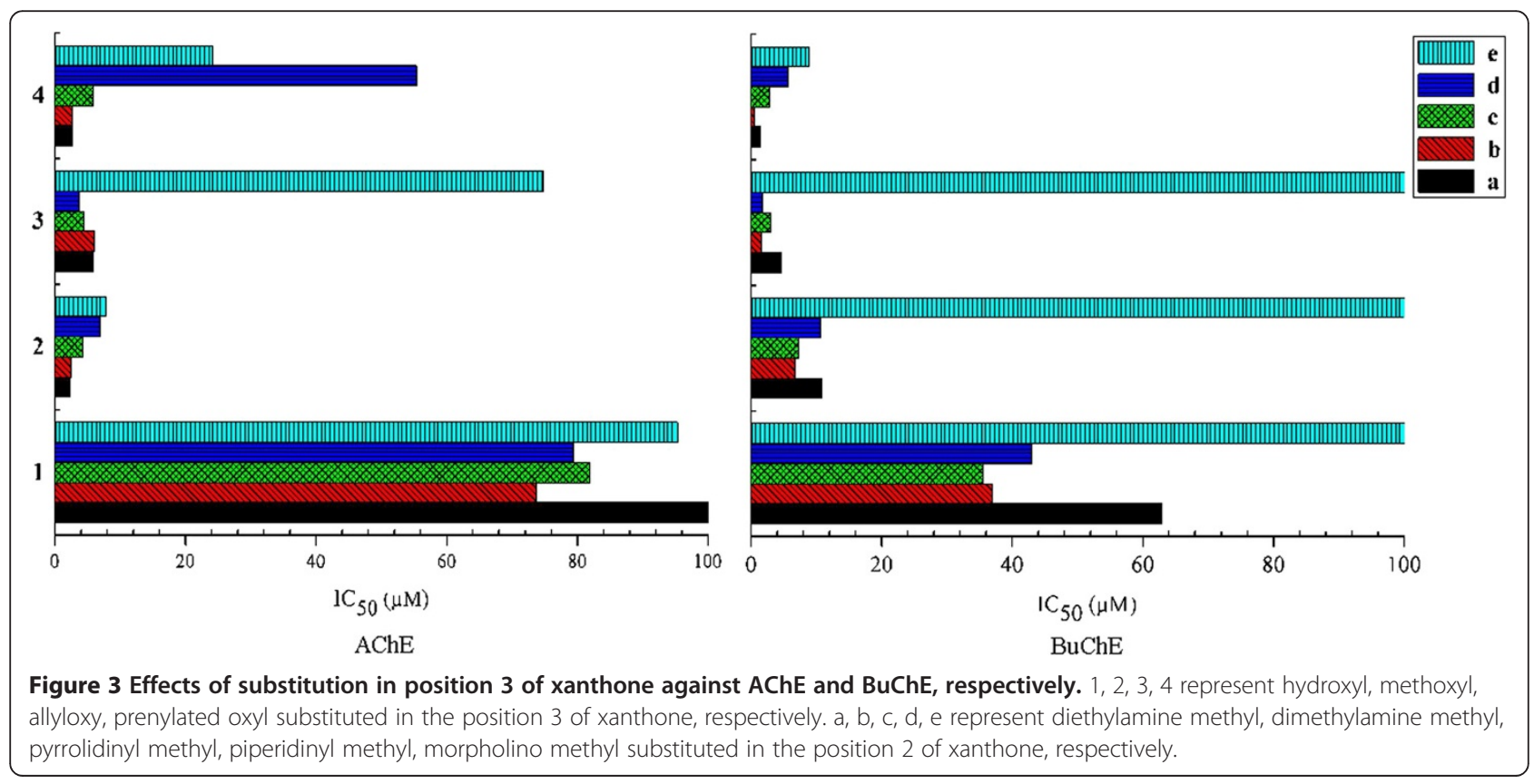



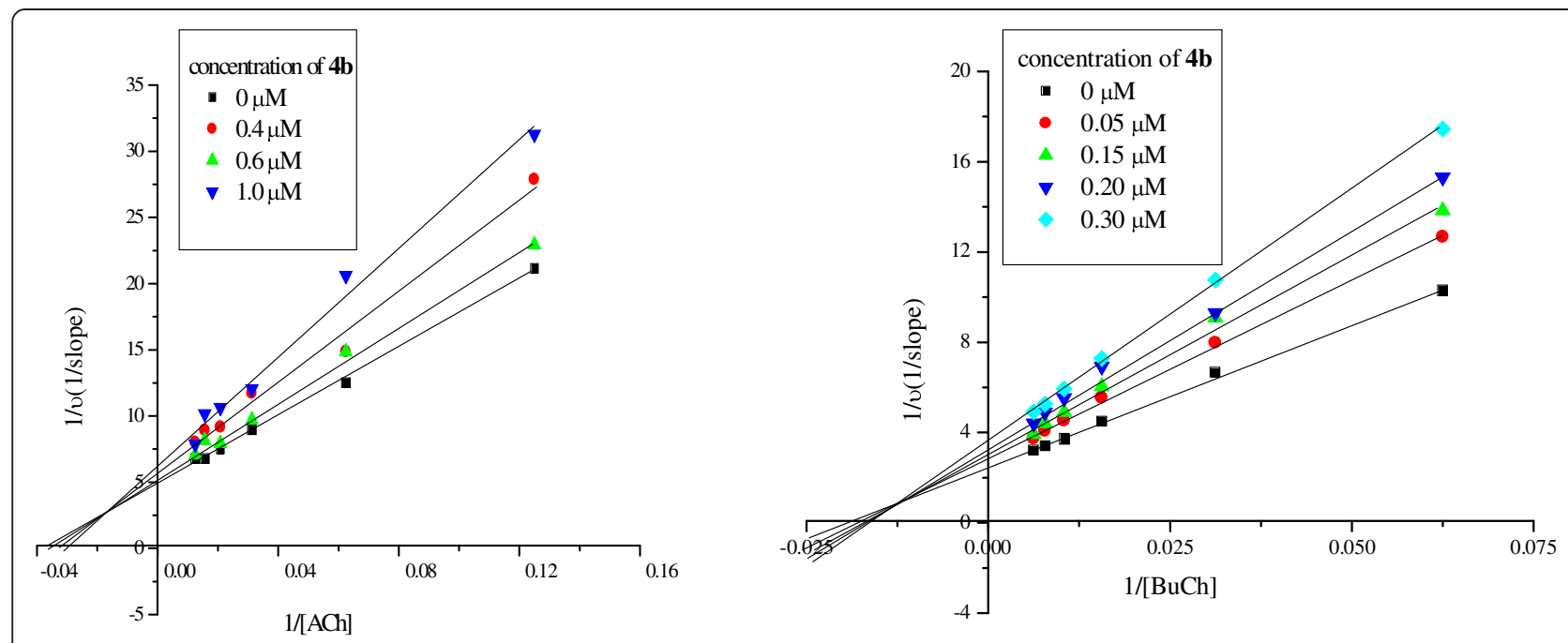

Figure 4 Lineweaver-Burk plots of AChE and BuChE inhibitory activity in the presence of compound $4 \mathrm{~b}$.

DTNB and thiocholine, which released by the hydrolysis of acetylthiocholine and butyrylthiocholine by AChE and BuChE, respectively, at the wavelength of $405 \mathrm{~nm}$ for $1 \mathrm{~min}$. Tested compounds and the positive control (Galantha-mine $\cdot \mathrm{HBr}$ ) were dissolved in DMSO at a concentration of $10 \mathrm{mM}$ before used and diluted in phosphate buffer to the required concentration. All the reactions were performed in triplicate in 96-well microplates in Microplate reader ELX808 ${ }^{\mathrm{rtw}}$ (BioTek). The concentrations of tested compounds that inhibited the hydrolysis of substrates (acetylthiocholine and butyrylthiocholine) by $50 \%$ $\left(\mathrm{IC}_{50}\right)$ were determined by monitoring the effect of increasing concentrations of these compounds in the assays on the inhibition values. The $\mathrm{IC}_{50}$ values were then calculated using the Origin 7.5.

\section{Enzyme kinetic assays}

The enzyme kinetic assays were followed the same method and the similar procedure. The total volume of tested solution in each well was also $150 \mu \mathrm{L}$. These containing phosphate buffer $118 \mu \mathrm{L}(0.1 \mathrm{M}, \mathrm{pH} 8.0)$, DTNB $6 \mu \mathrm{L}(4 \mathrm{mg} / \mathrm{mL}$ for $\mathrm{AChE}$ or $8 \mathrm{mg} / \mathrm{mL}$ for BuChE), different concentration of tested compounds solution $15 \mu \mathrm{L}$ and $\mathrm{AChE}$ or BuChE solution $5 \mu \mathrm{L}$, were mixed and incubated for $15 \mathrm{~min}$ at $37^{\circ} \mathrm{C}$. The reaction was then measured by the addition of different concentration of $(2.0,1.6,1.2,0.8,0.4,0.2 \mathrm{mg} / \mathrm{mL})$ acetylthiocholine or $(4.0,3.2,2.4,1.6,0.8,0.4 \mathrm{mg} / \mathrm{mL})$ butyrythiocholine solution with the volume of $6 \mu \mathrm{L}$. The hydrolysis of acetylthiocholine and butyrylthiocholine were monitored in 96-well micro-plates in Microplate reader ELX808 (BioTek) at the wavelength of $405 \mathrm{~nm}$ for $1 \mathrm{~min}$.
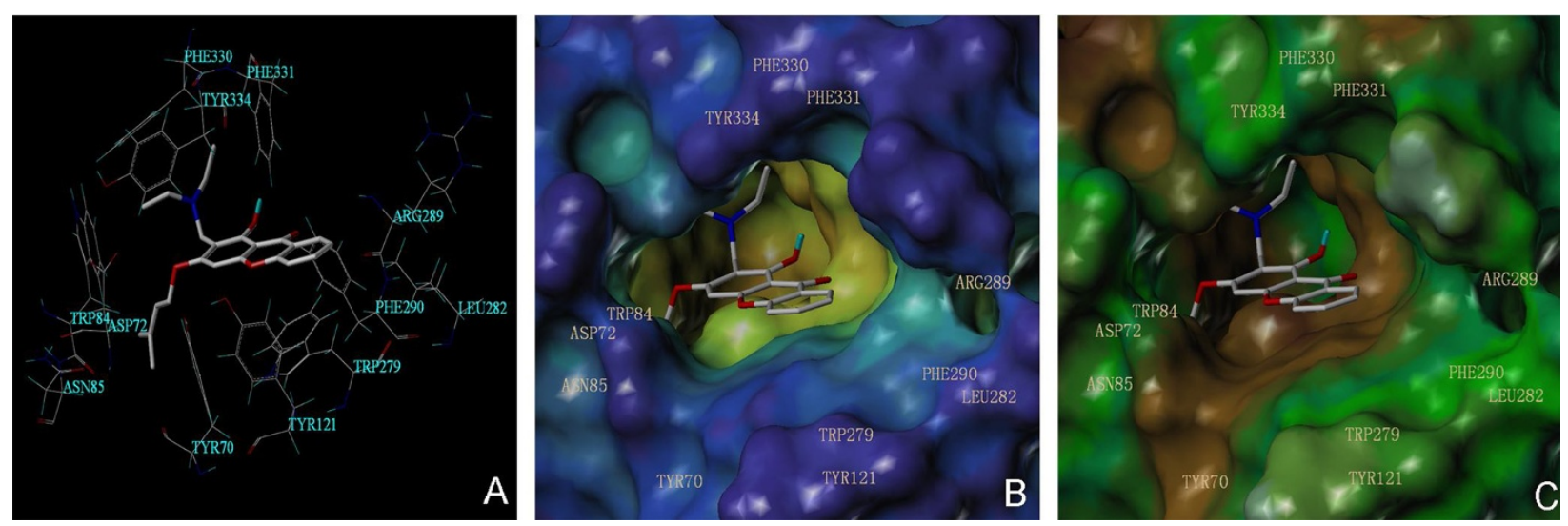

Figure $\mathbf{5}$ The binding mode research of compound $\mathbf{4 b}$ on $\mathbf{A C h E}$ by docking simulations. (A) Binding interactions with selected residues of the active site for compound $\mathbf{4} \mathbf{b}$. (B) The MOLCAD surfaces displayed with cavity depth potential of the binding pocket. (C) The MOLCAD surfaces of the binding pocket displayed with lipophilic potential. 

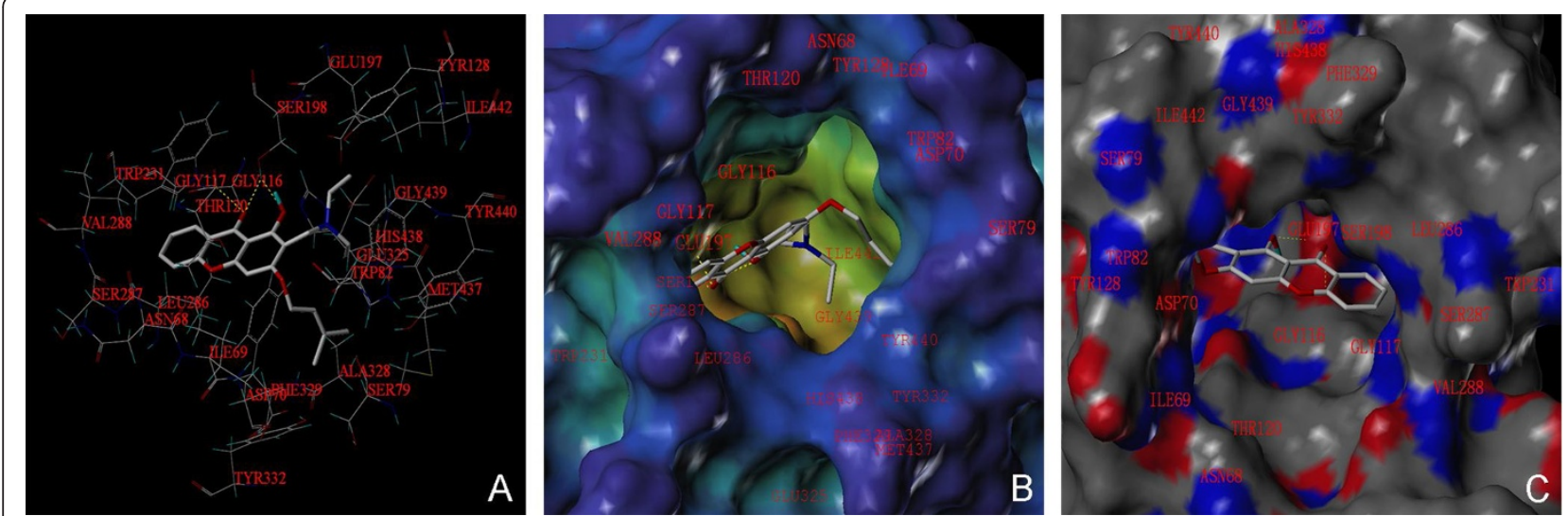

Figure 6 The binding mode research of compound $4 \mathbf{b}$ on BuChE by docking simulations. (A) The binding interactions with selected residues of the active site for compound $\mathbf{4 b}$. (B) The MOLCAD surfaces displayed with cavity depth potential of the binding pocket. (C) The MOLCAD hydrogen bonding surfaces of the binding pocket.

Lineweaver-Burk plots were obtained by plot reciprocal velocity versus substrate.

\section{Docking studies}

Docking studies were performed using the molecular modeling software package SYBYL 8.0 (Tripos, USA). The ligand was charged using the Gasteiger-Huckel and then subjected to energy minimization using the Powell's method with standard Tripos force field with a $0.01 \mathrm{kcal} /$ $($ mol*Å) gradient. The minimum-energy structure was used for the subsequent docking calculations. The crystal structures of $\mathrm{AChE}$ and $\mathrm{BuChE}$ retrieved from the Protein Data Bank (PDB) were used as the initial 3D structure. For AChE, the crystallographic ligand was extracted from the active site, and the resi-dues within a $6.5 \AA$ radius around the enzyme were defined as the active site. For $\mathrm{BuChE}$, the choline, water and cocrystallized small molecules were removed from the p-rotein structure firstly. After the addition of hydrogen and charges, the protein structure was minimized with Amber FF99 force field and 1000 steps. The active site of BuChE was generated by automatic mode implemented in Surflex-Dock program in SYBYL with default parameters. The Surflex-Dock program was used for the docking calculations and MOLCAD surfaces were generated for visualizing the binding mode of the docked protein-ligand complexes.

\section{Conclusions}

In conclusions, a series of Mannich bases of 1, 3dihydroxyxanthone derivatives were designed, synthesized and subjected to pharmacological evaluation. The results showed that the synthetic compounds possessed good to moderate cholinesterases inhibitory potency. The 1-hydroxy-3-methoxy substituted xanthone derivatives $(\mathbf{2 a} \sim 2 \mathbf{e})$ showed higher inhibitory effects on AChE. And the compounds with prenyl substitution in the position 3 of xanthone showed higher BuChE inhibitory potency. In addition, the compounds with diethylamine methyl at the end of the side chain in the position 2 of xanthone possessed higher inhibitory activity. Moreover, the compounds with alkyl substitutions in the position 3 of 1,3dihydroxyxanthone showed higher potent inhibitory activities compared to $\mathbf{1 a} \sim \mathbf{1 e}$ compounds with hydroxy in the position 3 . Kinetic analysis suggested that the the Mannich base compound inhibited both cholinesterases in mixed-type manners, suggesting they might simultaneously interact with the AS and PAS of both enzymes. Molecular docking studies were carried out to further investigate the binding modes of Mannich base derivatives with both cholinesterases, and the result was consistent with that of kinetic analysis. Finally, our results indicated that these new compounds represent useful templates for the development of new anti-AD agents.

\section{Additional file}

Additional file 1: contains the experimental details of preparation and characterization of the relational compounds in the paper.

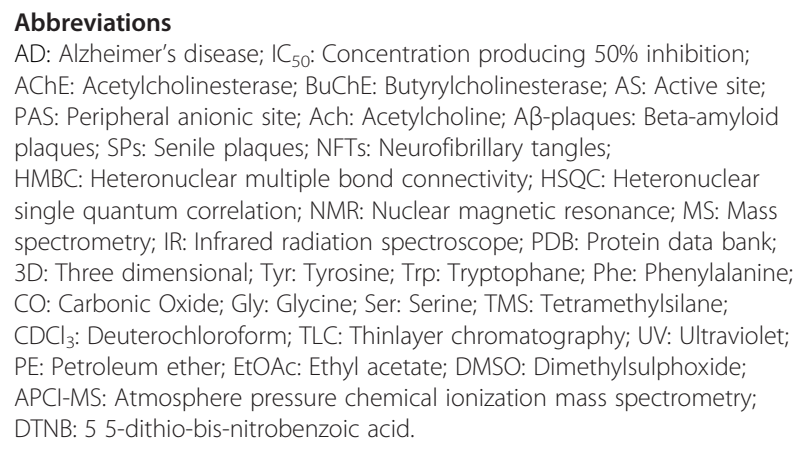




\section{Competing interests}

The authors declare that they have no competing interests.

\section{Authors' contributions}

The whole project was designed and directed by JQ and HW. WL, JH and HT synthesized and characterized the compounds. The bioassay was perfomed by WL. Molecular docking study was carried out by ZL. JQ wrote the manuscript and HW revised it. All authors read and approved the final manuscript.

\section{Acknowledgements}

This work was financially suported by grants from the National Natural Science Foundation of PRC (21002015), 973 project (2011CB512005), Natural Science Foundation of Guangxi (2010GXNSFB013013, 0639030, 2010GXNSFF013001) and Key Laboratory for the Chemistry and Molecular Engineering of Medicinal Resources (Guangxi Normal University), Ministry of Education of China (0710900114).

\section{Author details}

${ }^{1}$ Key Laboratory of Medicinal Chemical Resources and Molecular Engineering of State Education Ministry, College of chemistry \& Chemical Engineering, Guangxi Normal University, Guilin 541004, P.R. China. ${ }^{2}$ Guangzhoujinan Biomedicine Research and Development Center, Guangdong Provincial Key Laboratory of Bioengineering Medicine, Institute of Biomedicine, Jinan University, Guangzhou 510632, P.R. China.

Received: 12 February 2013 Accepted: 8 April 2013 Published: 27 April 2013

\section{References}

1. Wright Cl, Geula C, Mesulam MM: Neuroglial cholinesterases in the normal brain and in Alzheimer's disease: Relationship to plaques, tangles and patterns of selective vulnerability. Ann Neurol 1993, 34:373-384.

2. Price DL, Sisodia SS, Borchelt DR: Alzheimer disease-when and why? Nat Genet 1998, 19:314-316.

3. Luo Y: Alzheimer's disease, the nematode Caenorhabditis elegans, and ginkgo biloba leaf extract. Life Sci 2006, 78:2066-2072.

4. Lau LF, Schachter JB, Seymour PA, Sanner MA: Tau protein phosphorylation as a pherapeutic parget in Alzheimer's pisease. Curr Top Med Chem 2002, 2:395-415.

5. Doraiswamy PM: Non-cholinergic strategies for treating and preventing Alzheimer's disease. CNS Drugs 2002, 16:811-824.

6. Bartus RT, Dean RL III, Beer B, Lippa AS: The cholinergic hypothesis of geriatric memory dysfunction. Science 1982, 217:408-417.

7. Bartus RT: On neurodegenerative diseases, models and treatment strategies: Lessons learned and lessons forgotten a generation following the cholinergic hypothesis. Exp Neurol 2000, 163:495-529.

8. Hardy JA, Higgins GA: Alzheimer's disease: The amyloid cascade hypothesis. Science 1992, 256:184-185.

9. Whitehouse PJ, Price DL, Struble RG, Clark AW, Coyle JT, Delon MR: Alzheimer's disease and senile dementia: Loss of neurons in the basal forebrain. Science 1982, 211:1237-1239.

10. Ohyagi Y: Intracellular Amyloid $\beta$-protein as a therapeutic target for treating Alzheimei's disease. Curr Alzheimer Res 2008, 5:555-561.

11. Yamin G, Ono K, Inayathullah M, Teplow DB: Amyloid $\beta$-protein assembly as a therapeutic target of Alzheimer's disease. Current Pharm Design 2008, 14:3231-3246

12. Inestrosa NC, Alvarez A, Pérez CA, Moreno RD, Vicente M, Linker C, Casanueva OI, Soto C, Garrido J: Acetylcholinesterase accelerates assembly of amyloid- $\beta$-peptides into Alzheimer's fibrils: Possible role of the peripheral site of the enzyme. Neuron 1996, 16:881-891.

13. Tasker A, Perry EK, Ballard CG: Butyrylcholinesterase: Impact on symptoms and progression of cognitive impairment. Expert Rev Neurotherapeutics 2005, 5:101-106.

14. Furukawa-Hibi Y, Alkam T, Nitta A, Matsuyama A, Mizoguchi H, Suzuki K, Moussaoui S, Yu QS, Greig NH, Nagai T: Butyrylcholinesterase inhibitors ameliorate cognitive dysfunction induced by amyloid-[beta] peptide in mice. Behav Brain Res 2011, 1:222-229.

15. Darvesh S, Cash MK, Reid GA, Martin E, Mitnitski A, Geula C: Butyrylcholinesterase is associated with $\beta$-amyloid plaques in the transgenic APPSWE/PSEN1dE9 mouse model of Alzheimer disease. J Neuropathol Exp Neurol 2012, 71:2-14.

16. Perry EK, Perry RH, Blessed G, Tomlinson BE: Changes in brain cholinesterases in senile dementia of Alzheimer type. Neuropathol Appl Neurobiol 1978, 4:273-277.

17. Giacobini E: Cholinesterase inhibitors: New roles and therapeutic alternatives. Pharmacol Res 2004, 50:433-440.

18. Greig NH, Utsuki 1T, Yu QS, Zhu XX, Holloway HW, Perry TA, Lee B, Ingram DK, Lahiri DK: A new therapeutic target in Alzheimer's disease treatment: Attention to butyrylcholinesterase. Curr Med Res Opin 2001, 17:159-165.

19. Mohamed T, Rao PPN: Alzheimers disease: emerging trends in small molecule therapies. Curr Med Chem 2011, 18:4299-4320.

20. Na Y: Recent cancer drug development with xanthone structures. J Pharm Pharmacol 2009, 61:707-712.

21. Gao XM, Yu T, Cui MZ, Pu JX, Du X, Han QB, Hu QF, Liu TC, Luo KQ, Xu HX Identification and evaluation of apoptotic compounds from Garcinia oligantha. Bioorg Med Che. Lett 2012, 22:2350.

22. Pinto MMM, Sousa ME, Nascimento MSJ: Xanthone derivatives: New insights in biological activities. Curr Med Chem 2005, 12:2517-2538.

23. Li GL, He JY, Zhang AQ, Wan YQ, Wang B, Chen WH: Toward potent a-glucosidase inhibitors based on xanthones: A closer look into the structure-activity correlations. Eur J Med Chem 2011, 46:4050-4055.

24. Rampa A, Bisi A, Valenti P, Recanatini M, Cavalli A, Andrisano V, Cavrini V, Fin L, Buriani A, Giusti P: Acetylcholinesterase inhibitors: Synthesis and structure-activity relationships of $\omega$-[N-methyl- $\mathrm{N}-(3-$ alkylcarbamoyloxyphenyl)- methyl]aminoalkoxy heteroaryl derivatives. J Med Chem 1998, 41:3976-3986.

25. Belluti F, Rampa A, Piazzi L, Bisi A, Gobbi S, Bartolini M, Andrisano V, Cavalli A, Recanatini M, Valenti P: Cholinesterase inhibitors: Xanthostigmine derivatives blocking the acetylcholinesterase -induced $\beta$-amyloid aggregation. J Med Chem 2005, 48:4444-4456.

26. Piazzi L, Belluti F, Bisi A, Gobbi S, Rizzo S, Bartolini M, Andrisano V, Recanatini M, Rampa A: Cholinesterase inhibitors: SAR and enzyme inhibitory activity of 3-[ $\omega$-(benzylmethylamino)alkoxy] xanthen-9-ones. Bioorgan Med Chem 2007, 15:575-585.

27. Khan MTH, Orhan I, Senol FS, Kartal M, Sener B, Dvorská M, Smejkal K, Slapetová T: Cholinesterase inhibitory activities of some flavonoid derivatives and chosen xanthone and their molecular docking studies. Chem-Biol Interact 2009, 181:383-389.

28. Nian GL, Shu LS, Min ZS, Yu PT, Zhi HS, Hao T, Qian PS, Yi FF, Jian AD: Mannich bases of Scutellarein as thrombin-inhibitors: Design, synthesis, biological activity and solubility. Bioorgan Med Chem 2012, 20:6919-6923.

29. Liu Y, Ma L, Chen WH, Wang B, Xu ZL: Synthesis of xanthone derivatives with extended $\pi$-systems as a-glucosidase inhibitors: Insight into the probable binding mode. Bioorgan Med Chem 2007, 15:2810-2814.

30. Grover PK, Shah GD, Shah RC: Xanthones. IV. A new synthesis of hydroxyxanthones and hydroxybenzophenones. J Chem Soc 1955:3982-3985.

31. Reddy MVB, Su CR, Chiou WF, Liu YN, Chen RYH, Bastow KF, Lee KH, Wu TS: Design, synthesis, and biological evaluation of Mannich bases of heterocyclic chalcone analogs as cytotoxic agents. Bioorgan Med Chem 2008, 16:7358-7370.

32. Chipeleme A, Gut J, Rosenthalb PJ, Chibale K: Synthesis and biological evaluation of phenolic Mannich bases of benzaldehyde and (thio) semicarbazone derivatives against the cysteine protease falcipain-2 and a chloroquine resistant strain of Plasmodium falciparum. Bioorgan Med Chem 2007, 15:273-282.

33. Kintsurashvili LA, Sikharulidze MI, Buyanov VN, Turabelidze DG: Synthesis of amino derivatives of 1,6,8-trihydroxy-3-methyl-9,10-anthraquinone. Chem Nat Compd 1999, 35:619-620.

34. Pretsch E, Bühlmann P, Affolter C: In Structure Determination of Organic Compounds Table of Spectral Data. Edited by Rong GB, Zhu SZ. Shanghai, East China: University of Science and Technology Press; 2002:197. in Chinese.

35. Westerman PW, Gunasekera SP, Uvais M, Sultanbawa S, Kazlauskas R: Carbon -13 NMR study of naturally occurring xanthones. Org Magn Reson 1977, 9:631-636.

36. Ellman GL, Courtney KD, Andres VJ, Featherstone RM: A new and rapid colorimetric determination of acetylcholinesterase activity. Biochem Pharmacol 1961, 7:88-95.

37. Piazzi L, Cavalli A, Belluti F, Bisi A, Gobbi S, Rizzo S, Bartolini M, Andrisano V, Recanatini M, Rampa A: Extensive SAR and computational studies of 3-\{4- 
[(Benzylmethylamino)methyl] phenyl\}-6,7-dimethoxy-2H-2-chromenone (AP2238) derivatives. J Med Chem 2007, 50:4250-4254.

38. Rivera-Becerril E, Joseph-Nathan P, Pérez-Álvarez VM, Morales-Ríos MS: Synthesis and biological evaluation of (-)- and (+)- Debromoflustramine $B$ and its analogues as selective butyrylcholinesterase inhibitors. J Med Chem 2008, 51:5271-5284.

39. Vellom DC, Radic' Z, Li Y, Pickering NA, Camp S, Taylor P: Amino acid residues controlling acetylcholinesterase and butyrylcholinesterase specificity. Biochemistry 1993, 32:12-17.

40. Masson P, Froment MT, Bartels CF, Lockridge O: Asp70 in the peripheral anionic site of human butyrylchilinesterase. Eur J Biochem 1996, 235:36-48.

41. Nicolet Y, Lockridge O, Masson P, Fontecilla-Camps JC, Nachon F: Crystal structure of human butyrylcholinesterase and of its complexe with substrate and products. J Biol Chem 2003, 278:41141-41147.

42. Harel M, Sussman JL, Krejci E, Bon S, Chanal P, Massoulie J, Silman I: Conversion of acetylcholinesterase to butyrylcholinesterase: Modeling and mutagenesis. Proc Natl Acad Sci USA 1992, 89:10827-10831.

43. Cygler M, Schrag JD, Sussman JL, Harel M, Silman I, Gentry MK, Doctor BP: Relationship between sequence conservation and three-dimensional structure in a large family of esterases, lipases, and related proteins. Protein Sci 1993, 2:366-382.

44. Kaplan D, Ordentlich A, Barak D, Ariel N, Kronman C, Velan B, Shafferman A Does "butyryllization" of acetylcholinesterase through substitution of the six divergent aromatic amino acids in the active center gorge generate an enzyme mimic of butyrylcholinesterase? Biochemistry 2001, 40:7433-7445.

doi:10.1186/1752-153X-7-78

Cite this article as: Qin et al: Synthesis and biological evaluation of 1, 3-dihydroxyxanthone mannich base derivatives as anticholinesterase agents. Chemistry Central Journal 2013 7:78.

\section{Publish with ChemistryCentral and every scientist can read your work free of charge \\ "Open access provides opportunities to our colleagues in other parts of the globe, by allowing anyone to view the content free of charge." \\ W. Jeffery Hurst, The Hershey Company. \\ - available free of charge to the entire scientific community \\ - peer reviewed and published immediately upon acceptance \\ - cited in PubMed and archived on PubMed Central \\ - yours - you keep the copyright \\ Submit your manuscript here: \\ http://www.chemistrycentral.com/manuscript/<smiles>c1ccccc1</smiles> \\ Chemistry Central}

